\title{
O meio ambiente à luz do direito constitucional à educação
}

\section{The environment the light of the constitutional right to education}

\author{
Aline Oliveira Mendes de Medeiros ${ }^{1}$; Sadiomar Antonio Dezordi ${ }^{2}$
}

\begin{abstract}
Resumo
Foi pesquisado neste artigo sobre a importância do meio ambiente para a vida humana, analisando-o como extensão ao direito à vida, sendo considerado como núcleo da dignidade da pessoa humana, esta que por sua vez, compreende pedra basilar para a edificação do Estado Democrático de Direito. Consciente desta importância única é que se propõe atuar com base na educação como meio de transmitir estes valores e construir um Estado sustentável. Conhecedor desta premissa é que a Polícia Militar Ambiental de Santa Catarina criou o programa Protetor Ambiental, que visa levar educação para os jovens extraindo-o das margens da sociedade e acolhendo-os junto a polícia, transmitindo valores aos mesmos com enfoque na área ambiental. O método utilizado foi o qualitativo realizado através de pesquisas bibliográficas e análise de casos. A conclusão a que se chegou é que a educação compreende um meio que poderá trazer bons resultados, compreendendo uma base sólida na busca de consolidar a conscientização sobre a importância do meio ambiente para a vida humana no núcleo social.
\end{abstract}

Palavras-chaves: Direito educacional. Dignidade da pessoa humana. Estado socioambiental. Polícia militar de Santa Catarina. Programa protetor ambiental.

\begin{abstract}
Was researched in this article on the importance of the environment to human life, analyzing it as an extension of the right to life and is considered as the core of human dignity, this in turn, comprises a foundation stone for the building of a Democratic State. Aware of this importance only does it propose to act on the basis of education as a means of transmitting these values and build a sustainable state. Knowledgeable of this premise is that the Environmental Police of Santa Catarina created the Environmental Guard program, which aims to bring education to the young extracting it from the margins of society and welcoming them at the police, transmitting values to them focusing in the environmental area. The method used was the qualitative accomplished through literature searchs and case studies. The conclusion that was reached is that education comprises a medium that can bring good results, comprising a solid foundation in the quest to consolidate awareness of the importance of the environment to human life in the social core.
\end{abstract}

keywords: Education law. Human dignity. Environmental status. Military police of Santa Catarina. Environmental shield program.

\footnotetext{
${ }^{1}$ Graduanda em Direito; Autora do Blog Direito em Estudo; Articulista assídua em diversas revistas jurídicas; pesquisadora na área ambiental, militar e de segurança pública, e-mail: linny.mendes@hotmail.com

${ }^{2}$ Capitão do $5^{\circ}$ Batalhão da Polícia Militar Ambiental de Chapecó. Professor na Universidade do Oeste de Santa Catarina; Bacharel em Segurança Pública pela Universidade do Vale do Itajaí (UNIVALI) - 2007; Bacharel em Direito (UNOESC) - 2010. Possui Curso de Especialização em Policiamento Ambiental (PMSC) - 2008; Curso de Pós-Graduação "Lato Sensu” em nível de Especialização em Gestão e Direito Ambiental (com enfoque em Auditoria Ambiental) - Faculdade Padre João Bagozzi - 2010; Curso de Pós-Graduação "Lato Sensu” em nível de Especialização - MBA Auditoria e Perícia Ambiental - UCEFF - em curso. E-mail: 925791@pm.sc.gov.br.
} 


\section{Introdução}

Os referidos autores pesquisaram acerca da visão constitucional do meio ambiente,que se pauta na construção de um Estado Sustentável ${ }^{1}$ e para este fim, aposta na educação como meio de descortinar e reeducar os seres humanos. Esta pesquisa se justifica na fundamentalidade que possui este bem para a vida humana, sendo considerado como extensão ao direito à vida e núcleo integrante da dignidade da pessoa humana.

Esta pesquisa possui o método qualitativo, teve como base pesquisas doutrinária e a realização de um estudo de caso junto à $5^{\text {a }}$ Companhia da Polícia Militar Ambiental de Chapecó/SC, efetuando uma análise ao programa Protetor Ambiental desenvolvido em todo o Estado de Santa Catarina.

$\mathrm{O}$ que motivou a investigação foi a importância do tema para a atualidade em vista de que a sobrevivência humana circunda na qualidade do meio ambiente, fato este que o coloca como pressuposto de uma vida digna, sendo que bens como a água potável, ar puro, solo fértil e etc., são recursos naturais que estão além do poder aquisitivo, posto que são finitos e não há possibilidade de recriá-los através do dinheiro, desencadeando guerras e mortes devido à escassez e à má qualidade.

O objetivo consiste em apresentar um caso concreto relevante dentro desta temática que consiste no programa Protetor Ambiental destacando a importância da matéria, avultando na abertura do Estado para construir políticas públicas que visem proteger e restituir este bem, redirecionando o modo de vida dos cidadãos para um atuar pautado na sustentabilidade e para alcançar este fim é que o manuscrito em comento aposta na educação como prevenção, como meio de ação.

\section{A Dignidade da Pessoa Humana Como Pedra Basilar na Contrução do Estado Constitucional Ambiental}

A ideia de dignidade originou-se em Kant, baseando-se na racionalidade do homem, em sua autonomia de vontade, no sentido de poder se autodeterminar e assim agir em conformidade com o ordenamento jurídico, atributo este encontrando apenas nas pessoas, que para o mesmo fundamentava a ideia de dignidade humana, fato este que o colocava no patamar de "um fim em si mesmo" e não somente um meio para uso arbitrário de vontades do soberano.

Para Kant (apud SARLET, 2015, p. 33) os seres que dependiam da natureza compreenderiam seres irracionais, possuindo um valor relativo e por isto sendo considerados meios e não fim, por este motivo sendo chamados de "coisas", ao invés de pessoas como os seres racionais, denotando uma visão totalmente antropológica e centralizada no homem. A qualidade intrínseca e insubstituível da pessoa humana consiste no fato de que:

\begin{abstract}
[...] no reino dos fins tudo tem um preço ou uma dignidade. Quando uma coisa tem um preço, pode pôr-se em vez dela qualquer outra como equivalente; mas quando uma coisa esta acima de todo preço, e portanto não permite equivalente, então tem ela dignidade... Esta apreciação da pois a conhecer como dignidade o valor de uma tal disposição de espírito e põe-na infinitamente acima de todo preço. Nunca ela poderia ser posta em cálculo ou confronto com qualquer coisa que tivesse um preço, sem de qualquer modo ferir sua santidade. (KANT, apud SARLET, 2015, p. 33).
\end{abstract}

Mesmo sendo uma visão ultrapassada é neste doutrinador que baseia-se o fundamento da dignidade, neste sentido, já em XVII, autores como Blaise Pascal (apud SARLET, 2015, p. 34), evidenciavam este excessivo antropocentrismo afirmando que a dignidade não seria encontrada no espaço, "mas na ordenação do pensamento".

${ }^{1}$ Modelo estatal que visa a sustentabilidade, ou seja, a evolução através do respeito e da promoção do meio ambiente. 
Por isto é que o entendimento atual de dignidade compreende a proteção da vida em geral, "ainda mais numa época em que o reconhecimento da proteção do meio ambiente como valor fundamental indica que não mais está em causa apenas a vida humana, mas a preservação de todos os recursos naturais, incluindo todas as formas de vida existentes no planeta", mesmo que seja sob a justificativa de que esta proteção constituiria, "exigência da vida humana e de uma vida humana com dignidade".

Ademais, há de se questionar em que ponto iniciase a dignidade e em que ponto encerraria a mesma, seria através do embrião, através do biodireito, encerrando-se ao final da vida especialmente em questões que envolvem a eutanásia?

O que é irrefutável em qualquer discussão é que a dignidade da pessoa humana afasta qualquer modo de coisificação e instrumentalização do ser humano. Por consequência destaca Hegel (apud SARLET, 2015, p. 37) que "cada um deve ser pessoa e respeitar os outros como pessoas (sei eine Person undrespektiere die anderenalsPersoben)".

Este entendimento vislumbra que todos devem ser reconhecidos como pessoas, em vista de que a $\mathrm{CF} / 88$ determina a igualdade entre os seres humanos frente à lei, desta forma o autor não condiciona a garantia da dignidade à racionalidade humana Neste aporte:

\begin{abstract}
Da concepção jusnaturalista - que vivenciava seu apogeu justamente no século XVIII - remanesce, indubitavelmente, a constatação de que uma ordem constitucional que - de forma direta ou indireta consagra a ideia da dignidade da pessoa humana, parte do pressuposto de que o homem, em virtude tãosomente de sua condição humana e independentemente de qualquer outra circunstancia, é titular de direitos que devem ser reconhecidos e respeitados por seus semelhantes e pelo Estado. (SARLET, 2015, p. 39).
\end{abstract}

Mesmo que as definições efetuadas deem uma luz na direção do significado e alcance desta garantia é difícil precisar com exatidão seu núcleo protetivo devido suas características de "ambiguidade e porosidade", posto que diferente do que ocorre com outros direitos fundamentais a dignidade humana retrata qualidade inerente do ser humano, de forma que passou a ser considerada como um valor que identifica o ser humano, definição esta que não contribui no âmbito jurídico, devido ao fato de que sua visão focalizar apenas no homem, no sentido de que, para uma definição contribuir é preciso que a mesma seja geral, aberta as modificações que ocorrem no seio social.

Ademais, mesmo que não seja possível precisar um rol de violações em seu âmago, a dignidade é algo real que precisa ser efetivado principalmente ao evidenciar seu posicionamento constitucional que alcança o Art. 1, inc. III da Carta Política, enfocando sua compreensão de pilar constitucional, isto é, pedra basilar para a construção do Estado Democrático de Direito, sem a qual não há o que se falar em Democracia, ou em ordem jurídica, posto que um Estado que não buscasse a dignidade de seus cidadãos, consistiria em um órgão arbitrário e opressor, incapaz de prover uma vida saudável a seus cidadãos.

Desta feita, o direito emergiu como meio de regular as relações entre os indivíduos, promovendo um equilíbrio entre as forças, sendo este o âmago abarcado pela dignidade.

Por este motivo é que o ordenamento jurídico se desenvolve em torno da mesma, promovendo suas dimensões o mais amplamente possível, de forma a regular as relações entre os indivíduos e destes com os demais elementos do meio ambiente. No entanto, não se tenciona afirmar que esta garantia contemple um valor absoluto e soberano, porém, não há como negar seu valor.

Por defluência, salienta Marmelstein (2013, p. 16) que a dignidade é infringida sempre que alguém venha a ser descaracterizado como pessoa, sendo tratado como coisa, ideia esta aberta e insuficiente, pois que esta garantia vai além:

[...] onde não houver respeito pela vida e pela integridade física e moral do ser humano, onde as condições mínimas para uma existência digna não forem asseguradas, onde não houver uma limitação 
do poder, enfim, onde a liberdade e a autonomia, a igualdade em direitos e dignidade e os direitos fundamentais não forem reconhecidos e assegurados, não haverá espaço para a dignidade da pessoa humana. (SARLET, 2015, p 48).

Nos primórdios a dignidade servia como auferimento da proeminência social de uma pessoa, sendo estas pessoas definidas como membros de classe superiores conforme Hill Junior (apud GOLDSCHMIDT, 2009, p. 20), ou seja, uma pessoa era digna conforme a posição que esta ocupava na polis. Assim para Rabenhorst (apud GOLDSCHMIDT, 2009, p. 21):

Somente atenienses do sexo masculino, filhos de atenienses e no perfeito gozo de suas liberdades, possuíam cidadania. Só esses poucos privilegiados eram assegurados os direitos à igualdade (isonomia) e ao pleno exercício da palavra (isêgoria). Mulheres, escravos e estrangeiros não participavam da vida pública por serem considerados inferiores em virtude de sua própria natureza.

Esta visão de exclusão social utilizandose da dignidade é um fator que perdurou por séculos, conservando-se até a atualidade, verificável no pensamento antropocêntrico que domina o homem, fazendo com que este exclua os demais seres humanos desta garantia, fato este totalmente contrário aos preceitos da Carta Magna, posto que o meio ambiente compreende extensão da vida, visto que sem seus recursos naturais seria impossível a sobrevivência da espécie humana.

Foi através dosestoicos ${ }^{2}$ que os indivíduos passaram a serem vistos sob o olhar da igualdade, afastando as discriminações entre eles na teoria, posto que na prática constata-se a existência de discriminações das mais diversas espécies até a contemporaneidade, caso contrário, não existiriam tantas leis refutando este crime como o regramento jurídico atual possui.
Assim, o homem que se coloca como ser superior é incapaz de proteger e respeitar a si mesmo e ao seu semelhante, precisando estar constantemente vigiado e rodeado por leis para poder conviver com sua própria espécie, o mesmo procura encontrar atributos que o afastam de sua condição original (primitiva), porém, apenas se aproxima. Por isto é que emerge a necessidade de descortinar a visão do homem sobre a fundamentalidade do meio ambiente e sua unicidade para a sobrevivência.

A dignidade da pessoa humana, como, aliás, já tem sido largamente difundido, assume a condição de matriz axiológica do ordenamento jurídico, visto que é a partir desse valor e princípio que os demais princípios (assim como as regras) se projetam e recebem impulsos que dialogam com os seus respectivos conteúdos normativo-axiológicos, o que não implica aceitação da tese de que a dignidade é o único valor a cumprir tal função nem a adesão ao pensamento de que todos os direitos fundamentais (especialmente se assim considerados os que foram como tais consagrados pela Constituição) encontram seu fundamento direto e exclusivo na dignidade da pessoa humana. (SARLET; FENSTERSEIFER, 2014, p. 45).

Neste sentido a dignidade humana, acima de ser um valor constitucional compreende respeito e proteção à vida. É esta quem edifica o Estado, como constata os referidos autores (2015, p. 45) visto que conforme o pensamento pós-guerra "o Estado existe em função da pessoa humana, e não o contrário, já que o ser humano constitui a finalidade precípua, e não meio da atividade estatal", fato este que expressa à igualdade de forças entre Estadocidadão, em virtude da ação e efetividade dos direitos fundamentais.

Este princípio engloba uma dimensão social, implicando um olhar social e humanitário, atuando em diversas perspectivas, incluindo uma dimensão ecológica, in verbis:

[...] que por sua vez, também, não poderá ser restringida a uma dimensão puramente biológica ou física, pois contempla a qualidade de vida como um

${ }^{2} \mathrm{O}$ estoicismo (do grego $\left.\Sigma \tau \omega \imath \kappa \imath \sigma \mu o ́ s\right)$ é uma escola de filosofia helenística fundada em Atenas por Zenão de Cítio no início do século III a.C. Os estoicos ensinavam que as emoções destrutivas resultam de erros de julgamento, e que um sábio, ou pessoa com "perfeição moral e intelectual", não sofreria dessas emoções. 
todo, inclusive do ambiente em que a vida humana (mas também a não humana) se desenvolve. É importante, aliás, conferir um destaque especial para as interações entre a dimensão natural ou biológica da dignidade humana e a sua dimensão ecológica, sendo que esta última objetiva ampliar o conteúdo da dignidade da pessoa humana no sentido de assegurar um padrão de qualidade, equilíbrio e segurança ambiental (e não apenas no sentido da garantia da existência ou sobrevivência biológica), mesmo que, nas questões biológicas, muitas vezes esteja em causa a própria existência (e, portanto, sobrevivência) natural da espécie humana, para além mesmo da garantia de um nível de vida com qualidade ambiental. (SARLET; FENSTERSEIFER, 2014, p. 46).

A Carta Política de 88 assentou os valores ecológicos em todo o Estado, inclusive no que tange a dimensão da dignidade, abrangendo a ideia de um Estado de bem-estar ambiental, englobando um mínimo existencial ecológico, como meio para uma vida digna e segura, através da disponibilidade de água potável, ar puro, alimentos com qualidade, disponibilização de paisagens e etc., concretizando a vida humana em um percentual digno.

Assim não há como afastar o meio ambiente da dignidade humana, visto que são valores que se complementam com vistas a materializar uma vida com dignidade. Conforme enfatizado, o meio ambiente encontra-se "presente nas questões mais vitais e elementares da condição humana, além de ser essencial à sobrevivência do ser humano como espécie animal natural" de acordo com Sarlet e Fensterseifer (2014, p. 46).

Por consequência, o economista americano Jeffrey Sachs ${ }^{3}$, um dos precursores da Metas do Milênio, criou o projeto da ONU que embasa um conjunto de objetivos para reduzir a pobreza extrema (encerra neste ano - 2015), denominado Metas do Desenvolvimento Sustentável, que baseia-se para além de reduzir a pobreza, incluindo também a segurança e proteção ambiental, bem como a redução das desigualdades.

Este economista publicou um livro denominado The Age of Sustainable Development, que reclama por uma ação governamental tendente a reduzir o aquecimento global.

O referido autor ${ }^{4}$ define a seca em escala mundial como problemática, pois acredita que a vida terrestre está ameaçada, devido a escassez de água, fato este, que está gerando conflitos sociais, pois este problema já desencadeou até guerra, a exemplo da Síria, e a tendência é aumentar, caso as pessoas não se conscientizem sobre a gravidade do tema.

Este país enfrenta um de seus mais longos períodos de escassez, fator de deslocamento de aproximadamente 1 milhão de pessoas, causando inquietação social, aumento nos preços de alimentos, o que eclodiu na guerra.

Ocorre que o mundo encontra-se deslocado deste problema. Fala-se em desenvolvimento sustentável, porém, pouco se faz, um país fica na dependência de atitudes concretas de outro e assim nenhum materializa política alguma. Falta uma ação coletiva.

É necessária a elaboração de cálculos para construir políticas públicas. Ocorre que a precipitação da chuva decaiu, porém a população apenas aumentou, mister se faz a elaboração de um planejamento urbano, é preciso uma visão longínqua que vise construir planos a longo prazo.

Neste viés, um meio para preparar a sociedade e descortiná-la desta importância elementar do meio ambiente compreende a educação, tema chave para este manuscrito.

Neste enfoque, salienta Alexy (2009, p. 10) que, embora como regra geral o direito e as leis coincidam, "o direito não é igual à totalidade das leis escritas", pois o Estado pode exceder-se ou deixar de positivar leis que seriam necessárias aos indivíduos.

\footnotetext{
${ }^{3}$ Extraído do sítio: <http://exame.abril.com.br/revista-exame/edicoes/1085/noticias/secas-como-a-de-sao-paulo-vao-se-espalhardiz-jeffrey-sachs>.

4 Ver em: Sachs (2015), disponível em:

$<$ http://exame.abril.com.br/revista-exame/edicoes/1085/noticias/secas-como-a-de-sao-paulo-vao-se-espalhar-diz-jeffrey-sachs.>
} 
É para isto que existem as garantias fundamentais que englobam em seu núcleo as prerrogativas essenciais que a Carta Magna envolvendo com seu manto protetor e irradiando suas diretrizes para o restante do ordenamento jurídico, vinculando-o em sua orientação.

É neste ponto que se encontra o meio ambiente, portador de um capítulo próprio na Constituição devido ao seu cunho elementar e positivado em diversas outras orientações legais, sendo irrefutável seu caráter de direito fundamental, seja por sua essencialidade a vida humana, seja por sua extensa gama de positivação ou destaque que a Constituição lhe dá.

\section{A Educação Sob o Olhar Jurídico}

A educação possui uma relação intrínseca com o direito em vista de compreender condição de ascensão do indivíduo, tanto pessoal quanto social, e o sistema jurídico como meio de realização humana e social, não se dissocializa desta realidade, englobando em seu sistema normas e princípios de garantia ao acesso educacional.

No que reporta à Boaventura (apud GOLDSCHMIDT, 2009, p. 47) a educação abarca três características, sendo elas, "faculdade atribuída ao educando, norma que rege comportamento de ensino e ramo da ciência jurídica, isto é, o direito educacional".

Como possibilidade, tem sido considerado como um direito fundamental de todos indistintamente, conforme letra do art. 205 do Caderno Constitucional, compreendendo direito social e dever estatal, devendo ser incentivada através da comunidade.

No entanto, no que reporta a educação fundamental, esta consiste em uma obrigação (gratuita) e não faculdade, conforme art. 208, inc. I da Carta Magna. Sendo reafirmado por meio dosarts. 54 e 55 do Estatuto da Criança e do Adolescente - Lei n 8.069/90 (BRASIL, 1990).
De outra forma, a educação sob o prisma de norma, é compreendida por uma sistemática de regramentos sobre o ensino e aprendizagem. Ademais, no que diz respeito a sua estrutura e desenvolvimento, não se confunde a legislação do ensino com o direito à educação, pois de acordo com Motta:

\begin{abstract}
No primeiro sentido, temos uma pletora de normas que vão desde leis federais, estaduais e municipais até pareceres do Conselho Nacional de Educação, decretos do Poder Executivo, portarias ministeriais, estatutos e regimentos das escolas, que constituem a conhecida tradicional disciplina Legislação do Ensino, a qual é parte integrante, mas restrita, do Direito Educacional, pois não inclui nem a unidade doutrinária, nem a sistematização de princípios, nem tampouco a metodologia que estrutura um corpo jurídico pleno. (apud GOLDSCHMIDT, 2003, p. 48).
\end{abstract}

Por consequência, observado como ciência jurídica, Goldschmidt (2003, p. 48) destaca que o "o direito educacional identifica-se por possuir um conjunto de princípios, normas e institutos próprios, sobre os quais, através de métodos típicos, produz-se uma considerável doutrina e jurisprudência". Como contempla um direito social, a educação é exigível pelo cidadão, sendo protegida por garantias constitucionais como meio de efetivar a prestação educacional do Estado.

Dentre as leis que disciplinam o acesso à educação encontra-se a Lei $n^{\circ}$ 9.394/96, Lei de Diretrizes e Bases da Educação Nacional (BRASIL, 1996), que disciplina a organização, princípios, finalidades, níveis e modalidades no que reporta à educação nacional. Neste sentido, destaca Souza (apud GOLDSCHMIDT, 2003, p. 49):

Os princípios que regem a educação nacional, enunciados no texto constitucional, devem ser ajustados, na sua aplicação a situações reais, que envolvem: o funcionamento das redes escolares, a formação dos especialistas docentes, as condições de matrículas, aproveitamento de aprendizagem e promoção de alunos, os recursos financeiros, materiais, técnicos e humanos para o desenvolvimento do ensino, a participação do 
poder público e da iniciativa particular nos esforços educacional, a superior administração dos sistemas de ensino, as peculiaridades que caracterizam a ação didática nas diversas regiões do país, etc. São esses ajustamentos, essas diretrizes nascidas das bases inscritas na Carta magna, que se constituem na matéria-prima de uma Lei de Diretrizes e Bases da Educação Nacional.

No aspecto formal, o direito educacional define a necessidade da readaptação e adequação do tema pelo professor de forma a inseri-lo de forma interdisciplinar, sem que necessite estar inserindo uma nova disciplina, mas apenas inserindo seus conteúdos nos currículos escolares, em conformidade com o art. 10 da Lei em expressão.

Os conteúdos são organizados em três blocos: a) ciclos da natureza: objetiva ampliar e aprofundar o conhecimento da dinâmica das interações ocorridas na natureza, para que consigam avaliar as alterações na realidade local e a gravidade dessa alteração irreversível de ecossistemas; b) sociedade e meio ambiente: as relações entre o ser humano e o meio ambiente, e a busca de alternativas de relação entre sociedade e natureza; c) meio ambiente $e$ conservação ambiental: analisa as interferências positivas e negativas dos seres humanos no meio ambiente, buscando discutir as formas adequadas de intervenção humana para equacionar melhor os seus impactos. (CAPENA, 2011, p. 742, grifos do original).

Como reafirmação desta lei, o ECA disponibiliza o Capítulo IV (arts. 53/59) para disciplinar a matéria, garantindo às crianças e adolescentes o direito a desenvolver-se plenamente, através da educação, preparando-o para a cidadania e o exercício profissional, assegurando igualdade de condições e direito ao respeito. (BRASIL, 1990).

Nada obstante, a Lei de Diretrizes e Bases da Educação Nacional - Lei n 9.394/1996 (BRASIL, 1996), compreende fonte para as demais prerrogativas sobre a temática, abraçando e concretizando princípios constitucionais acerca da matéria. Ao lado de todo este aplanado de regras, este direito possui autonomia jurídica, posto que embasa institutos jurídicos próprios.

Por decorrência, em conformidade com o art. $6^{\circ}$ da Expressão Maior a educação compreende um direito social, no entanto, o Estado não reservara apenas para si tal encargo, compartilhando tal dever de prestação também com a família e com a sociedade, da qual aguarda o incentivo e auxilio em sua prestação, bem como um dever precípuo.

Por corolário, a CF/88 disciplinou o art. 209 disciplinando a livre iniciativa privada, de forma a atender a demanda social, disciplinando tal princípio desde o art. $1^{\circ}$, inciso IV, onde define a livre iniciativa, transpondo para as cláusulas pétreas, art. $5^{\circ}$, inc. XVIII, dando liberdade de associação, passando então para o art. 170 da norma em comento, garantindo que no que diz respeito à ordem econômica, sua finalidade consiste em valorizar o trabalho humano e a livre iniciativa, de forma a assegurar a todos uma existência digna. (BRASIL, 1988).

Nada obstante, destaca Platão (apud SANTOS, 1949, p. 17) que "a principal função do Estado é a Educadora," bem como, V. Hugo (apud SANTOS, 1949, p. 17) enfatizava que "abrir escolas é fechar cadeias"

No mesmo enfoque assevera Dewey (apud SANTOS, 1949, p. 17) que "a educação é o progresso contínuo de reconstrução da experiência, destinado a dotar a vida do indivíduo dum conteúdo sempre mais vivo e mais largo e, ao mesmo tempo, a dar a este indivíduo um poder de controle sempre maior sobre o próprio processo educativo".

Neste sentido, Bagley (apud SANTOS, 1949, p. 17) define a educação como sendo "um processo pelo qual o indivíduo adquire experiência que lhe tornará mais eficiente a ação futura." Ademais enfatiza Thornidike (apud SANTOS, 1949, p. 17):

[...] é ao mesmo tempo ciência e arte, compreende a interpretação, o controle e a realização de mudanças promotoras de bem estar geral. Como ciência, ela se acha interessada na descoberta de ajustamentos satisfatórios do indivíduo ao meio; como arte, ela formula os processos de mudanças necessárias a semelhantes ajustamentos, na própria natureza humana. 
De outra forma é a educação que prepara o ser humano, física, intelectual, psíquica e moralmente para viver em sociedade, portanto, emerge a necessidade de uma educação que atue desde a infância de forma a preparar um cidadão para o mundo.

Ou seja, educá-lo e condicioná-lo em conformidade com a lei e aos parâmetros sociais de maneira a inseri-lo em igualdade de condições ao meio social, prepará-lo para os anseios e expectativas da comunidade, pois que, quanto melhor e mais digna a educação que receba mais forte será a expectativa de formar nesta criança um cidadão consciente sobre as necessidades sociais, como por exemplo, respeitar o meio ambiente e evitar a criminalidade, como define Santos (1949, p. 26).

\section{A Educação Ambiental à Luz Lei Federal $\mathrm{N}^{\circ}$. 9795/99}

Ocorre que a educação ambiental é um assunto de suma relevância jurídica sendo a mesma firmada através da Carta Magna e disciplinada na Lei de 9.795/99 ou seja, a Lei da Política Nacional de Educação Ambiental(BRASIL, 1999), cuja qual, além de ser apregoada por inúmeros outros dispositivos tanto nacionais quanto internacionais.

Por defluência discorre o art. $225, \S 1^{\circ}$, IV da Epístola Maior que para que para dar o efetivo equilíbrio ao meio ambiente que tal artigo enseja no seu caput requer ao Poder Público, a promoção da educação ambiental, "em todos os níveis de ensino para que assim se crie uma conscientização pública para a preservação do meio ambiente", de acordo com Capena (2011, p. 742).

Neste sentido, Martins (apud CAPENA, 2011, p. 742) comenta, que o mesmo consiste em ir além de um direito, visto que:
[...] determina o constituinte que levar a sociedade a valorizar a preservação do meio ambiente é política de que os governos não podem abrir mão, para, através da educação, de um lado, e da conscientização, de outro, conseguir criar 'ambiente cultural' de perenização do 'ambiente natural', em face da própria fiscalização que a sociedade exercerá.

Ocorre que a visão antropocêntrica do homem como centro do universo, ou seja 'homo mensura', encontra-se tecnicamente superada, a partir do instante em que o ser humano percebera-se em uma situação de crise com o meio ambiente insustentável, onde a degradação a este bem passara a ameaçar o próprio bem estar e qualidade de vida social, ou mesmo, da própria sobrevivência, desencadeando em um processo que se denomina 'consciência ambientalista'. Assim perceptível se faz que na:

[...] Constituição Federal brasileira de 1988 podese, teoricamente, encontrar uma efetiva garantia para a preservação e recuperação da natureza, por meio dos dispositivos constitucionais ali sistematizados. Entretanto, isso não basta. Porque tal efetividade é resultante do direcionamento de diversos fatores, tais como as políticas públicas, o sistema econômico, a tecnologia de produção, os sistemas jurídicos e institucionais e, por fim a herança cultural. Todos esses fatores, aliados à construção de uma nova mentalidade que será alcançada por meio da implementação da educação como um todo e, completamente, com a educação ambiental, devem estar focalizados em uma única e primordial finalidade: dotar o indivíduo de sólidos conhecimentos e argumentos teóricos que possibilitem uma maior compreensão das questões ambientais, e também dos desafios políticos, sociais, econômicos, culturais e ecológicos em que estamos envolvidos. O alcance de tal desiderato encontra alicerce e fundamentação num movimento nacional e internacional por uma sociedade local e global mais justa e ecologicamente sustentável. (CAPENA, 2011, p. 742-743).

Destaca-se que a educação ambiental vem expressa no art. $1^{\circ}$ da Lei 9.795/99, (BRASIL, 1999) definida como "os processos por meio dos quais o indivíduo e a coletividade constroem valores sociais, conhecimentos, habilidades, atitudes e competências voltadas para a conservação do meio ambiente." 
Por decorrência interpreta-se do artigo um posicionamento de reconciliação entre o homem e a natureza, de forma em que o mesmo tome consciência do valor e necessidade deste bem para a possibilidade de vida para o mesmo, de maneira a focar em uma abordagem socioambiental, voltando-se à preservação e regeneração da natureza.

Neste seguimento, o art. $2^{\circ}$ destaca que "a educação ambiental é um componente essencial e permanente da educação nacional, devendo estar presente de forma articulada, em todos os níveis e modalidades do processo educativo, em caráter formal e não formal," (BRASIL, 1999) isto é, o mesmo responsabiliza a toda a sociedade por sua promoção.

Já no artigo $3^{\circ}$ vem expresso o direito comum de todos à terem acesso a educação ambiental, sendo esta incumbida por meio do:

"I - Poder Público, nos termos dos arts. 205 e 225, da CF/1988, definir políticas públicas que incorporem a dimensão ambiental, promover a educação ambiental em todos os níveis de ensino e o engajamento da sociedade na conservação, recuperação e melhoria do meio ambiente." Lei $n^{\circ}$ 9.795/99 (BRASIL, 1999).

Nos artigos que se seguem o dispositivo menciona a responsabilidade das instituições educativas do Sistema Nacional do Meio Ambiente, "dos meios de comunicação de massa, das empresas, entidades de classe, entidades públicas e privadas e da sociedade como um todo na formação de valores, atitudes e habilidades que propiciem a atuação individual e coletiva"como denota Milaré (2011, p. 203), objetivada na prevenção, diagnóstico e solução da problemática ambiental.

A partir deste seguimento, entende-se que a educação ambiental é um direito fundamental do cidadão, compreendido no art. $5^{\circ}$ da $\mathrm{CF} / 88$, bem como em função de seu mérito ao bem estar do ser humano. No decorrer dos seus 21 artigos a referida lei buscara dirimir as dúvidas pedagógicas acerca da educação ambiental inter-relacionando a educação geral com a escolar.

Assim, sendo, encontra-se no capítulo II, Seção II, os critérios e normas para esta modalidade no ensino formal, em continuidade trás a Seção III, a expressão da educação informal, compreendendo as “ações e práticas educativas voltadas à sensibilização da coletividade sobre as questões ambientais e a sua organização e participação na defesa da qualidade do meio ambiente," conforme define Milaré (2011, p. 632).

A educação ambiental consiste em um instrumento destinado a formar e aguçar a consciência ecológica com vistas no exercício da cidadania. Em decorrência, verifica-se no art. $4^{\circ}$, inc. II da lei em comento que a educação ambiental tem como pilar o entendimento do meio ambiente em sua total abrangência e interdependência entre "o meio natural, o socioeconômico e o cultural, sob o enfoque da sustentabilidade."

Ocorre que, como patrimônio de uso coletivo o meio ambiente precisa ser assegurado e protegido, recuperando o que fora degradado e garantindo o que existe, por meio de ações conjugadas, pois que, efetivar uma não exclui a outra.

Atualmente o movimento ambientalista tomou espaço no território mundial, conseguindo fazer com que as pessoas entendam a necessidade de proteger o meio ambiente, levando aos cidadãos a negação desta visão antropocêntrica, passando a admitir uma ideologia ecocêntrica ${ }^{5}$ que leva em primazia os interesses do meio ambiente, devido à finitude deste bem e sua essencialidade para a vida humana.

Descortinando a sociedade para uma reflexão acerca do destino da Terra, posicionando a ética ambiental na comunidade terrestre, contando com fortes adeptos de diferentes ramos acadêmicos e

\footnotetext{
${ }^{5}$ Com base no respeito e promoção pelo meio ambiente.
} 
profissionais, denotando uma evolução no homem em acompanhamento dos avanços que o Planeta exige como forma de coexistência com o homem. Tal teoria baseia-se na reflexão acerca do sentido e valor que possui a vida, pois que:

Sendo a vida considerada o valor mais expressivo do ecossistema planetário (já que não se conhecem outras possíveis e eventuais formas de vida em outros astros, nos moldes em que a concebemos), concentrou-se grande ênfase no seu valor. Por isso, nas duas últimas décadas a Bioética estruturou-se para responder a questões práticas, ligadas a valores, principalmente em face das questões suscitadas pela Biotecnologia. (MILARÉ, 2011, p. 116-117).

Assim, o valor da vida passou a ter grande significado sempre que o homem venha a intervir no mundo natural, com base no ecocentrismo de forma a ampliar a racionalidade da humanidade acerca da crise ambiental que se instala e toma grandes proporções verificadas por meio da globalização, promovendo a ética acerca das questões ambientais.

Passa o homem a agir, portanto, de forma que suas atitudes não venham a ser maléficasao Planeta, pois que este compreende sua casa, atuando de maneira a excluir as atitudes predatórias e perversas do ser humano "que erode o Planeta e subtrai a sustentação dos sistemas vivos e das redes que conectam os componentes do ecossistema planetário", de acordo com o referido autor (MILARÉ, 2011, p. 116).

Por defluência, subtraindo e ceifando a vida da natureza, automaticamente a sociedade destrói sua própria capacidade de viver, pois que sua sobrevivência depende do meio natural para existir, assim, uma forma é dependente da outra, e nenhuma é mais importante que a outra, pois que estão conectadas e neste sentido é que devem ser vistas, garantidas, protegidas e recuperadas.

Neste enfoque, passa-se a definir a educação não formal, aspecto este, onde entra a ação da Polícia Militar Ambiental, como protetora e promovedora, item este definido a seguir.

\section{A Polícia Militar Ambiental Em Efetivação Da Lei 9.795/99}

No que reporta à educação, considerada sob o aspecto informal, a Educação Ambiental alude sobre os processos e ações de educação exteriores ao ambiente escolar, o que se denomina educação permanente, o que segundo Milaré (2011, p. 632), contribui "para aperfeiçoar a consciência dos problemas ambientais e para buscar soluções práticas para eles a partir de reflexões e debates dentro da própria comunidade em que o cidadão está inserido".

A necessidade por uma educação que satisfaça aos objetivos e necessidades culturais arrasta-a para uma constante atualização e renovação, de maneira a expandir seu campo de ação, pois que, o dever de educar não diz respeito apenas à família e à escola, indo além, pois que, compete a toda sociedade, representada por múltiplos seguimentos/órgãos, como no caso da Polícia Ambiental Militar.

A principal tarefa da educação ambiental é aproximar o cidadão do meio ambiente em uma visão holística, ou seja, analisando o meio ambiente de forma interdependente da sadia qualidade de vida da pessoa humana, revolucionando a atual concepção para um olhar protetivo e promotor, a partir da inserção da pessoa neste âmbito de reconhecimento da natureza e sua fundamentalidade para a vida humana, pois que a mesma "se faz para a comunidade e com a comunidade", como define Milaré (2011, p. 635).

Não se trata, neste instante, de impor padrões de ações, mas sim de verificar a partir da participação de cada cidadão em todas as ações que lhe dizem respeito, realizando-se em conjunto da comunidade.

Propõe-se uma compreensão integrada do meio ambiente e das múltiplas e complexas relações. A teia da realidade viva não se reduz aos elementos naturais do meio físico, mas estende-se a todas as formas de organização do espaço sobre o planeta Terra que se relacionem com a presença e com a ação do ser humano. (MILARÉ, 2011, p. 636). 
Neste ínterim, destaca-se que o poder de polícia atua em diversos setores da atividade humana, dentre estes se enfatiza a "polícia de caça, polícia florestal, polícia de tráfego e de trânsito, polícia de divertimentos públicos, polícia sanitária etc., advertindo, porém, que tal relação é 'simples enumeração, sem nenhum propósito de classificar ou sistematizar os campos de incidência da Polícia Administrativa", como denota Dawali (2011, p. 132).

Ocorre que o poder do Estado é indivisível e único, já o poder de polícia não compreende nem ao menos um poder "mas sim uma expressão do Poder, uma atribuição. A expressão Poder de Polícia Ambiental, por tanto, deve ser entendida como abreviação da expressão Poder de Polícia em Meio Ambiente ou Poder de Polícia em Matéria Ambiental", de acordo com o respectivo autor (DAWALI, 2011, p. 132). Assim:

\begin{abstract}
Nessas expressões, podem ser abrigados os diversos setores de incidência do Poder de Polícia relacionados à preservação do meio ambiente e da sadia qualidade de vida: polícia das águas (voltada para coibir o despejo de efluentes sem tratamentos de corpos d'água), polícia da atmosfera (para evitar o lançamento de poluentes na atmosfera), polícia de caça (para proteção da fauna terrestre), polícia de pesca, polícia florestal (para a proteção da vegetação), polícia de ruídos (cuja atividade volta-se à repressão da emissão abusiva de sons), polícia de construções (no que tange à repressão a parcelamentos de solos clandestinos - fontes de poluição - e a construções em áreas de proteção ambiental ou de preservação permanente não edificáveis) etc. (DAWALI, 2011, p. 132).
\end{abstract}

Seu fundamento basilar consiste na supremacia do interesse público, conforme destaca o art. 225 da CF/88, pois como direito difuso, o meio ambiente possui relação direta com o ser humano tanto sob o prisma social, quanto individual, como é possível verificar na letra deste artigo.

Nada obstante, a Polícia Militar Ambiental originou em Santa Catarina no ano de 1990, por meio da Lei $n^{\circ} 8.039$, sendo denominada como Companhia de Polícia Florestal, tendo como sede o Parque Estadual da Serra do Tabuleiro, no município de Palhoça/SC.

No entanto, no mês de maio do ano de 1992 a mesma sofreu uma mudança na nomenclatura passando a chamar-se Polícia Florestal, com definição no Decreto $\mathrm{n}^{\circ} 1.783 / 92$, visando a promoção de sua tarefa constitucional que abrange a Proteção do Meio Ambiente de forma mais completa, através da:

[...] proteção da flora, fauna, solo, ar e recursos hídricos, aspectos culturais e intelectuais especialmente ligados a preservação da natureza e combates às poluições. Em 1993 passou a denominar-se Companhia de Polícia de Proteção Ambiental "Dr. Fritz Müller", Pai da Ecologia Catarinense, justa homenagem ao "Príncipe dos Observadores". (PROTETOR AMBIENTAL, 2015a).

No entanto, no município de Chapecó/SC, a Polícia Militar Ambiental teve origem apenas em 16 de setembro de 1996, possuindo um efetivo de 19 policiais e uma área de ação que abrangia 118 municípios.

Assim, as atribuições da Polícia Ambiental passa pela fiscalização ambiental, encaminhamentos judiciais, até os procedimentos administrativos, que compreendem ferramentas da mesma em proteção e recuperação dos recursos naturais, indispensáveis para uma vida digna.

Neste ínterim, a Polícia Militar Ambiental tem como objetivo atuar no presente preparando o futuro garantindo a paz e harmonia entre a sociedade e a natureza devido à interconexão existente entre as mesmas, pois que, uma complementa a existência da outra.

Ocorre que os atos do poder de polícia visam efetivar a proteção ao meio ambiente. Por decorrência, depreende-se que mesmo antes da promulgação da Carta Magna, já havia a lei $\mathrm{n}^{\circ}$ 6.938/81 (BRASIL, 1981), a qual previa uma Política Nacional do Meio Ambiente, objetivando a "preservação, melhoria e recuperação da 
qualidade ambiental propícia à vida, visando assegurar, no país, condições ao desenvolvimento socioeconômico, aos interesses da segurança nacional e à proteção da dignidade da vida humana", de acordo com o art. $2^{\circ}$ do dispositivo em comento.

Desta feita, as ações do poder de polícia consistem em instrumentos da efetividade da Política Nacional do Meio Ambiente. Destarte, conforme exposto, não se encerram nesta lei os atos incumbidos à Polícia Militar Ambiental, pois que, como sua função também se encontra a educação informal ${ }^{6}$, em conformidade com a Lei 9.795/99. Ocorre que:

Todo processo educacional, em tese, deve preparar o indivíduo para viver em sociedade, ou melhor, dizendo, para participar da vida da sociedade, contribuindo para que este alcance os seus objetivos maiores. Não há como ignorar o papel da Educação Ambiental nesse contexto, eis que ela está voltada para a preservação e o incremento de um bem per se de natureza social. (MILARÉ, 2011, p. 639).

Neste sentido tem-se no art. $1^{\circ}$, inc. III da Carta Magna a proteção da dignidade da pessoa humana, acerca da qual se pode dizer que:

De qualquer modo, o que importa, nesta quadra, é que se tenha presente a circunstância, oportunamente destacada por Gonçalves Loureiro, de que a dignidade da pessoa humana - no âmbito de sua perspectiva intersubjetiva - implica uma obrigação geral de respeito pela pessoa (pelo seu valor intrínseco como pessoa), traduzida num feixe de deveres e direitos correlativos, de natureza não meramente instrumental, mas sim relativos a um conjunto de bens indispensáveis ao 'florescimento humano'. (SARLET, 2015, p. 54).

Assim, não há o que se falar em viver se não for para viver dignamente, e para tal, somente se mostra possível, dentre outros aspectos, por meio de um meio ambiente sadio e equilibrado. Nada obstante:
[...] sempre haverá como sustentar a dignidade da própria vida de um modo geral, ainda mais numa época em que o reconhecimento da proteção do meio ambiente como valor fundamental indica que não mais está em causa a vida humana, mas a preservação de todos os recursos naturais, incluindo todas as formas de vida existentes no planeta, ainda que se possa argumentar que tal proteção de vida em geral constitua, em ultima analise, exigência da vida humana e de uma vida com dignidade. (SARLET, 2015, p. 35).

Ou seja, há quem ampare a possibilidade da dignidade para além do ser humano, abrangendo também a vida em geral, situação esta que não entra em discussão no artigo em pauta, mas enrobustece a necessidade da aplicabilidade da educação ambiental como meio de afirmar o valor que o meio ambiente possui na atualidade, valor este, ao qual a Polícia Militar Ambiental associase e efetiva por meio de suas ações, dentre as quais se destaca o Programa Protetor Ambiental.

\section{O Programa Protetor Ambiental Como Materialização Da Educação Ambiental}

Fortificado acerca da importância da educação para a sociedade, bem como, não menos importante, esclarecido sobre a questão do meio ambiente e sua necessidade de proteção e promoção para a garantia de sobrevivência terrestre é que a Polícia Militar criara o Programa Protetor Ambiental ${ }^{7}$, desenvolvido pelo $5^{\text {a }}$ Companhia de Polícia Militar Ambiental de Chapecó, bem como em todo o estado de Santa Catarina, o qual se volta à sociedade de maneira a apregoar a preservação e recuperação da natureza.

O programa é de origem catarinense e aborda todas as áreas referentes ao meio ambiente no período letivo (um ano), o referido programa foi criado no ano de 1999 e vem sendo desenvolvido na região desde então, no entanto, no município de Chapecó/SC, o próprio foi implantado somente

${ }^{6}$ É aquela promovida por outros meios que não seja o âmbito escolar, isto é, através da família, da comunidade, ou por outras instituições como a Polícia Militar Ambiental.

${ }^{7}$ Extraído do sítio do programa Protetor Ambiental. 
no ano de 2012, em virtude da necessidade de preparo profissional que o respectivo exige, requisitando mais que agentes com formação na área, mas também, recursos pecuniários para suprir com as obrigações existentes.

Sua faixa de atuação aborda os adolescentes, de maneira a trazê-los para junto da Polícia Militar Ambiental, aproximando-os da mesma e extraindoos da criminalidade e da ociosidade desenvolvendo atividades teóricas e práticas no que reporta ao meio ambiente, conscientizando-os sobre a necessidade de defender o meio ambiente, bem como difundindo a educação ambiental, modificando o comportamento social, resgatando e exercendo a cidadania de tais jovens em sua plenitude, garantindo aprendizado aos alunos, bem como os capacitando para agirem em prol do meio ambiente em sua comunidade.

Por defluência, ampliando e aprimorando o intelecto dos mesmos nesta área, descortinando-os acerca de uma visão pautada na dignidade e respeito ao meio ambiente em ações sociais, resgatando valores e fortalecendo o espírito de cooperação e integração entre os alunos, destacando sua capacidade de raciocínio como forma de interagir com a sociedade e promover o respeito ambiental, o programa visa atender jovens entre 12 e 14 anos e possui a durabilidade de um ano.

As turmas são formadas por no máximo 30 alunos, pois não visa a obtenção de um número alto de adeptos, mas sim, prestar um trabalho com efetividade, uma ação que procura mais que agir superficialmente, mas sim, formar pessoas aptas as necessidades que a atualidade impõe.

O referido programa encontra-se em execução trazendo excelentes resultados, pois, no decorrer destes 03 anos de implantação, apenas na região deste município já foram formados mais de 300 protetores. A dificuldade encontrada baseia-se na falta de apoio pecuniário de outras entidades, porém, está sendo superada, ao demonstrar a efetividade e benefícios do programa no núcleo social.

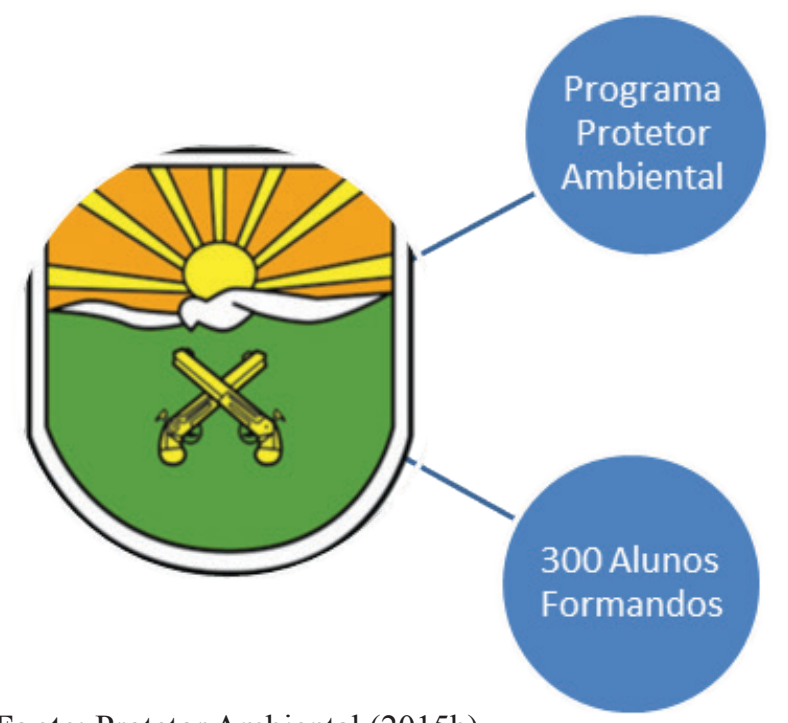

Fonte: Protetor Ambiental (2015b).

Difundindo a educação ambiental entre estes jovens pensantes, com capacidade de raciocínio lógico, transmitindo-lhes conhecimento, através dos instrutores, como meio de mudar o comportamento consumista e desregrado que paira na sociedade, conscientizando sobre a essencialidade do meio ambiente, habilitando estes adolescentes a agirem com consciência em seus atos, cientes de que a natureza é finita e como tal é a vida em si, motivo este que autoriza a necessidade de ações protetivas e promovedoras do respeito ambiental.

Neste programa os jovens recebem conhecimentos teóricos e práticos, fazem viagens para conhecer localidades e implantam suas ideias através de palestras desenvolvidas por eles mesmos à comunidade e através de outros modos de ação. Os instrutores não são apenas policiais, pois existem, também, de outras entidades da área ambiental, fato este que amplia o conhecimento destes jovens.

No programa os alunos obtém mais que educação ambiental, mas também, educação sexual, jurídica e outras pertinentes a faixa etária e a necessidade da região na qual o aluno se encontra. Traz aulas teóricas e práticas que incluem a participação dos cidadãos adultos, bem como, atividades em 
família, visando uma aproximação entre a PMA e toda a sociedade, interagindo em benefício do meio ambiente e das obrigações que cada região impõe aos seus indivíduos.

\section{Considerações Finais}

O trabalho discorreu sobre a importância impar do meio ambiente para a sobrevivência humana, sendo considerado como um direito essencial ao ser humano, contemplado como bem de extensão ao direito à vida e por este motivo, detentor de dignidade, sendo abraçado por esta garantia e fortalecido pela Carta Política de 1988.

Os recursos naturais são de suma relevância que possuem potência, inclusive para desencadear uma guerra civil, como no caso da Síria, conforme exposto no texto, devido a escassez de água.São responsáveis pelo deslocamento de milhões de pessoas, na busca pela melhoria da qualidade de vida, atuando diretamente na vida destes seres humanos, disponibilizando uma vida digna, com saúde e harmonia ou não, pois a vida em si gira em torno dos recursos naturais, sendo intrínseca a esta.

Como forma de transmitir este entendimento à sociedade é que este artigo baseia-se na educação, de maneira a atuar sobre o cidadão deste o início, descortinando-o para um agir com sustentabilidade.

Consciente desta concepção e aberta para estudos aprofundados foi que a Polícia Militar Ambiental criou o programa Protetor Ambiental, tencionando agir sobre os cidadãos trazendo-os para próximo da polícia, extraindo-os da criminalidade, atuando de maneira preventiva, transmitindo bons ensinamentos, com especialidade nos temas atinentes ao meio ambiente.

\section{Referências}

ALEXY, R. Conceito e validade do direito. Tradução de Gercélia Batista de Oliveira Mendes. São Paulo: Ed. WMF, 2009.
BRASIL. Constituição da República Federativa do Brasil. Disponível em: <http://www.planalto. gov.br/ccivil 03/Constituicao/Constituicao.htm>. Acesso em: $\overline{25}$ mar. 2015.

Decreto Lei $n^{\circ} 9.795 / 99$ de 27 de abril de 1999. Dispõe sobre a educação ambiental, institui a Política Nacional de Educação Ambiental e dá outras providências. Disponível em: <http://www. planalto.gov.br/ccivil_03/leis/19795.htm.>. Acesso em: 25 mar. 2015.

Lei $n^{\circ} 6.938 / 1981$. Dispõe sobre a Política Nacional do Meio Ambiente, seus fins e mecanismos de formulação e aplicação, e dá outras providências. Disponível em: <http://www.planalto.gov.br/ ccivil 03/leis/16938.htm. . . Acesso em: 25 mar. 2015 .

Lei $n^{\circ}$ 8.069/90, de 13 de julho de 1990. Dispõe sobre o estatuto da criança e do adolescente e dá outras providências. Disponível em: $<$ http:// www.planalto.gov.br/ccivil_03/leis/18069.htm.>. Acesso em: 25 mar. 2015.

BRASIL. Lei $n^{\circ}$ 9.394, de 20 de dezembro de 1996. Estabelece as diretrizes e bases da educação nacional. Disponível em: $<$ http://www.planalto.gov. br/ccivil 03/leis/19394.htm. . . Acesso em: 25 mar. 2015.

CAPENA, C. Educação ambiental: ferramenta para criação de uma nova consciência planetária. In: MILARÉ, É.; MACHADO, P. A. L. (Org.). Doutrinas essenciais: direito ambiental. São Paulo: Revista dos Tribunais, 2011. (Doutrinas Essenciais, v. 1).

DAWALI, M. O poder de polícia em matéria ambiental. In MILARÉ, É.; MACHADO, P. A. L. (Org.). Doutrinas essenciais: direito ambiental. São Paulo: Revista dos Tribunais, 2011. (Doutrinas Essenciais, v. 1).

GOLDSCHMIDT, R. $O$ princípio $d a$ proporcionalidade no direito educacional. Passo Fundo: UPF, 2003.

Flexibilização dos direitos trabalhistas: ações afirmativas da dignidade da pessoa humana como forma de resistência. São Paulo: LTr, 2009. 
MARMELSTEIN, G. Curso de direitos fundamentais. 4. ed. São Paulo: Atlas, 2013.

MILARÉ, É. Direito do ambiente: a gestão ambiental em foco, doutrina, jurisprudência, glossário. 7. ed. São Paulo: Ed. dos Tribunais, 2011.

PROTETOR AMBIENTAL. Disponível em: $<$ http://protetor-ambiental.webnode.com/.>. Acesso em: 25 mar. 2015a.

. Histórico da polícia militar ambiental. Disponível em: $<$ http://protetor-ambiental. webnode.com/.>. Acesso em: 25 mar. 2015b.

SANTOS, M. Educação como prevenção da criminalidade. Rio de Janeiro: [s. n], 1949.

SACHS, J. Secas como a de São Paulo vão se espalhar, diz Jeffrey Sachs. Disponível em: <http:// exame.abril.com.br/revista-exame/edicoes/1085/ noticias/secas-como-a-de-sao-paulo-vao-seespalhar-diz-jeffrey-sachs>. Acesso em: 25 mar. 2015.

SARLET, I. W. Dignidade da pessoa humana e direitos fundamentais na Constituição Federal de 1988. 4. ed. Porto Alegre: Livraria do Advogado, 2015.

SARLET, I. W.; FENSTERSEIFER, T. Princípios do direito ambiental. São Paulo: Saraiva, 2014. 
